Karen O'Grady

\title{
Zoombrarian
}

\section{Using Zoom to provide personalized database instruction}

I was recently enrolled in an excellent evidenced-based nursing course. My classmates were nursing educators. None of them were librarians. As part of the course, one of the university's medical librarians gave us a PubMed searching lesson. In my rare role as a student of database searching rather than as a librarian, I had an epiphany.

Passively watching a librarian search a database is so incredibly boring and hard to follow that even I checked out. She perfectly executed the kind of PubMed demonstration we all regularly provide for classes, and there was nothing egregiously incorrect about her presentation. Experiencing the lesson from the other side of the virtual desk, however, sharply revealed to me how ineffectual this method of instruction is. I resolved never to teach that way again.

I have long suspected that individual attention is the only way to effectively teach database searching. Students are interested in searching only their own topics. Few will be able to apply a librarian's hypothetical search demonstration to their own searching. Watching a librarian search PubMed is about as unrelatable as watching someone shop for their own groceries.

One disconnect that makes demonstrations boring and ineffectual for students is the understandable tendency of librarians to perform a practiced and seamless search, using exactly the right search terms with no discernable trial and error. Even demonstrating a planned misfire that brings zero results to make a point does not guarantee students' comprehension of that point. Librarians often present a flawless demonstration of a database's features to arrive at a perfectly executed search. This potentially sets up today's Googling generation of students to believe their searches will go just as smoothly, and that database searching is a snap. It can make students feel frustrated when they sit down to search and are not able to locate articles as quickly and seamlessly as the librarian did.

Also, most librarians erroneously assume that the point of demonstrating a database for students is the same as when they conduct an actual search: to arrive at that triumphant final step where a reasonable number of relevant articles are located. This satisfying conclusion for a librarian is usually not experienced in the same way from the students' perspective. Any students who might still be paying attention do not grasp that the lesson has victoriously concluded. This tried-and-true method of teaching database searching simply does not teach database searching. Demonstrating is not always teaching. Watching is not always learning.

I have been teaching database searching to graduate nursing students with a method that uses the virtual environment inflicted upon higher education by the COVID-19 pandemic.

Karen O'Grady is nursing librarian at the University of San Diego's Hahn School of Nursing, email: kogrady@sandiego.edu 
When students email me research questions, I respond by recording a quick informal Zoom video for them. I share my screen and click around while I think out loud about their question or topic. I record the video off the top of my head, and I brainstorm ideas, potential search terms, my opinion on their PICO questions, and whatever else comes to me that might help them. I speak directly to the students, addressing them by name.

Most of the questions involve PubMed searching, so I narrate my thought process and teach database navigation skills while I search. I am convinced that half the skill of database searching for students accustomed to the instant gratification of Google lies in learning to navigate. I spend time explaining and defining some of the more useful advanced search fields, such as title/abstract and text word. I emphasize that using these features will save students time. I repeatedly explain how to click from the MeSH screen to the search history screen and then back to the screen containing articles. A large part of the lesson is not about articles or search terms, it is about navigation, which I think is missing from most librarians' instruction.

I strive to stick to information that will help the student in the moment rather than lecturing about all the databases' capabilities. It is paramount to me to come across as light and approachable and to downplay the intimidating expert librarian image. I call many of the techniques I demonstrate "cheats" or tricks so students can get what they need and move on. I strive to keep the videos less than ten minutes long and to avoid off-putting librarianese lingo. I chose plain language to explain concepts and vocabulary. I assume both that students know nothing and that they find library science boring. Most do.

I never do their homework for them. I only brainstorm a few ideas to get them thinking. I usually stop short of handing them search terms or locating articles for them. I email students my impromptu videos and suggest we Zoom together if they would like more help. Most students take me up on the offer, and some say the video was all they needed. I am proud to say nearly every student tells me the video was very helpful, and many students return later to ask me other questions.

I find sending recorded videos to be much more productive than Zooming with a student as a first response to an emailed inquiry. Every librarian has sat one-on-one with a student who got hung up on reading abstracts after an initial search produces 1,000 articles. We have all experienced the student who waits patiently (or sometimes impatiently) for us to locate articles for them or students who type and search inefficiently, not able to sit and listen to instruction about finding the right search terms. Getting my whole lesson out uninterrupted works better for both parties. The best thing about my recorded lessons is that they are personalized. The students are not watching boring hypothetical demonstrations on topics that do not pertain to them. My videos differ from generic instructional videos because they answer students' specific questions. They are human, friendly, and unrehearsed.

I am receiving glowing feedback on my personalized videos. Students tell me that listening to my train of thought is helpful. They love that they can watch the videos as many times as they need. I am receiving what I consider to be the ultimate proof that my videos are helpful-students reaching out to me at the suggestion of other students whom I have helped.

If I think a particular video demonstrates something other nursing students can use, I add it to the playlist of videos I created on my Nursing LibGuide. I point out the playlist when I give classroom presentations on library resources. I encourage students to watch the videos 
back-to-back, YouTube style, when they have a bit of leisure time. I believe the redundancy of my navigation explanations in brief video after brief video reinforces my teaching tips and tricks that students can apply to their own searching.

What I say here may seem like a stark contradiction to my earlier declaration about students learning nothing by watching a librarian search. The difference provided by the playlist is that students can watch, skip, and replay any videos in any way they prefer. They are not stuck in a class and subjected to a boring 30-or-60-minute rehearsed lesson focused on search results, as I was in my evidence-based nursing course. The personalized videos are brief. They are focused on navigating around the database. The unrehearsed stream of consciousness shows both my approachable personality and better demonstrates what actual searching looks like, misfires and all.

I have also added personalized videos on other topics to my playlist. They are responses to the types of reference questions we all receive-using interlibrary loan, locating specific articles, finding sources other than databases, and so on. When I point out the playlist to students, I guarantee that watching the videos will teach them something they did not know about using the library. Students, faculty, and even librarians from other universities have praised my videos. These efforts have created a successful ongoing project using Zoom in a virtual environment. Like many innovations that have resulted from our collective adjustment to this terrible pandemic, I am now proud and excited to call myself a Zoombrarian. $n$ 